\title{
Hubungan Motivasi Berprestasi dengan Kinerja Pegawai di Dinas Pendidikan dan Kebudayaan Kabupaten Lima Puluh Kota
}

\author{
Wela Agustia Wulandari 1, Nellitawati 2, Rusdinal 3, Yulianto Santoso 4 \\ Padang 4 \\ Wela Agustia Wulandari ${ }^{1}$, e-mail : welaagustia123@gmail.com \\ Nellitawati ${ }^{2}$, e-mail : nellitawati@ fip.unp.ac.id \\ Rusdinal ${ }^{3}$, e-mail : rusdinal@fip.unp.ac.id \\ Yulianto Santoso ${ }^{4}$, e-mail : yuliantosantoso2015@gmail.com
}

${ }^{1}$ Administrasi Pendidikan, Universitas Negeri Padang $1,{ }^{2}$ Administrasi Pendidikan, Universitas Negeri Padang

$2,{ }^{3}$ Administrasi Pendidikan, Universitas Negeri Padang $3,{ }^{4}$ Administrasi Pendidikan, Universitas Negeri

\begin{abstract}
This study aims to obtain information on whether there is a relationship between achievement motivation and employee performance. The purpose of this study was to obtain information on: 1) employee performance, 2) achievement motivation, and 3) the relationship between achievement motivation and employee performance. The population of all civil servants and non civil servant employees in the Department of Education and Culture of Fifty Cities Regency is 89 people. The sample used was 47 people who were obtained based on the use of the Slovin formula based on the Proportional Stratified Random Sampling technique. The use of this research instrument is the use of a Likert Scale with 5 selected answers it have test for validity and reliability. Validity and reliability were tested with the help of SPSS 16.0 with the Product Moment correlation formula. The results of the analysis show 1) high category employee performance, namely $89.58 \%, 2$ ) achievement motivation is in the high category $87.9 \%$, and 3) there is a clear relationship between achievement motivation and employee performance in the Education and Culture Office of Lima Puluh Kota Regency. That is, $r$ count $0.754>r$ table 0.288 and the $t$ value is $7.717>t$ table 2,000 at the $95 \%$ confidence level, which shows a relationship between achievement motivation and employee performance. This means that achievement motivation is one of the factors that influence the performance of employees in the Education and Culture Office of Fifty Cities Regency.
\end{abstract}

\begin{abstract}
Abstrak
Penelitian ini maksud nya untuk mendapatkan informasi adakah hubungan motivasi berprestasi dengan kinerja pegawai. Tujuan penelitian ini untuk mendapat informasi: 1) kinerja para pegawai, 2) motivasi berprestasi, dan 3) hubungan motivasi berprestasi dengan kinerja pegawai. Populasinya seluruh pegawai PNS dan pegawai Non PNS di Dinas Pendidikan dan Kebudayaan Kabupaten Lima Puluh Kota yang berjumlah 89 orang. Sampel yang digunakan berjumlah 47 orang yang diperoleh dengan berdasarkan penggunaan rumus slovin berbasiskan teknik Proportional Stratified Random Sampling. Penggunaan instrumen penelitian ini yakni pemakaian Skala Likert dengan 5 jawaban pilihan yang sudah diuji kevalidan serta reliabilitasnya. Validitas dan reliabilitas diuji dengan bantuan SPSS 16.0 dengan rumus korelasi Produk Moment. Hasil analisisnya menunjukkan 1) kinerja pegawai kategori tinggi yaitu 89,58\% ,2) motivasi berprestasi berada pada kategori tinggi $87,9 \%$, dan 3) adanya hubungan yang berarti antara motivasi berprestasi dengan kinerja pegawai di Dinas Pendidikan dan Kebudayaan Kabupaten Lima Puluh Kota yakninya $r$ hitung $0,754>r$ tabel 0,288 dan nilai $t$ hitung 7,717> $t$ tabel 2,000 di taraf kepercayaan 95\% yaitu menunjukkan adanya hubungan di antara motivasi berprestasi dengan kinerja pegawai. Artinya motivasi berprestasi merupakan salah satu faktor yang berpengaruh terhadap kinerja para pegawai di Dinas Pendidikan dan Kebudayaan Kabupaten Lima Puluh Kota.
\end{abstract}

\section{Kata Kunci: Motivasi Berprestasi dan Kinerja Pegawai}

How to Cite: Wulandari, Wela Agustia ${ }^{1}$, Nellitawati ${ }^{2}$, Rusdinal ${ }^{3}$ and Yulianto Santoso ${ }^{4}$. 2021. Hubungan Motivasi Berprestasi dengan Kinerja Pegawai di Dinas Pendidikan dan Kebudayaan Kabupaten Lima Puluh Kota. Journal Educational Administration and Leadership, Vol (N): pp. XX-XX, DOI:10.24036/XXXXXXXXXX-X-XX 


\section{Pendahuluan}

Sumber daya manusia adalah sebuah aset yang sangat penting bagi perusahaan atau organisasi . sebuah organisasi harus mempunyai sumber daya manusia yang kompeten dan memiliki kemampuan dalam melaksanakan dan menyelesaikan tugas tugas organisasi. Sebuah organisasi akan efektif terlaksana apabila sumber daya manusianya energik, memberikan segenap pikiran, kreativitas, keahlian dan kemampuan yang dimilikinya. Untuk tercapainya tujuan yang maksimal dalam suatu organisasi maka seorang pegawai harus mempunyai kinerja yang baik pula. Menurut (Mangkunegara, 2004) kinerja adalah hasil dari sebuah kemampuan yng dilaksanakkan dengan sepenuh hati oleh seoang pegawai

Tapi kenyataan di lapangan, pada pelaksanaan praktek lapangan manajemen pendidikan pada bulan desember 2019 sampai bulan februari 2020 khususnya di Dinas Pendidikan dan Kebudayaan Kabupaten Lima Puluh Kota terdapat beberapa fenomena yang menggambarkan kinerja yang rendah: 1) terdapatnya sebagian pegawai kurang bertanggung jawab terhadap pekerjaan. Hal ini terlihat dari pegawai yang menunda-nunda pekerjaan dan bekerja apa adanya, 2) Masih ada sebagian pegawai yang belum melakukan pekerjaan tidak maksimal dan tidak sesuai dengan kenyataan yang ditetapkan, dan 3) Kurangnya kerjasama antar pegawai satu dengan pegawai lainnya. Hal ini terlihat dari sikap kurang peduli dan merasa tidak senang terhadap rekan kerjanya ketika di embankan tugas.

Terdapat beberapa dorongan yang bisa mempengaruhi kinerja seorang pegawai. Diantaranya adalah motivasi. Motivasi adalah dorongan yang timbul dari dalam maupun luar diri seorang. Motivasi dalam menjalankan sebuah pekerjaan sangat mempengaruhi bagaimana hasil kerja seorang pegawai tersebut semakin baik dan tinggi motivasi yang dimiliki pegawai maka semakin efektif dan maksimal kinerja yang diberikan pegawai tersebut untuk organisasinya. Dhermawan, Sudibya, dan Utama dalam (Nelitawati, n.d.) menyatakan bahwa motivasi adalah bagian dari elemen yang dapat mempengaruhi seseorang kompetensi dalam menjalankan tugasnya. Motivasi yang muncul dari dalam diri individu itulah yang dinamakan motivasi. (Gistituati, 2009) mengatakan bahwasannya ketika seorang pegawai atau pekerja rajin, ulet serta kreatif dan inovatif dalam bekerja itu menandakan adanya motivasi diri yang muncul pada pegawai tersebut yang sangat berdampak baik bagi kinerja tersebut.

Namun berdasarkan pengamatan kemajuan organisasi di lapangan pada pelaksanaan praktek lapangan manajemen pendidikan pada bulan desember 2019 sampai februari 2020 khususnya di Dinas Pendidikan dan Kebudayaan Kabupaten Lima Puluh Kota penulis menemui beberapa fenomena diantaranya: 1) terdapat beberapa pegawai yang masih kurang bahkan tidak bersemangat dalam bekerja, 2) Masih ada beberapa pegawai yang kurang disiplin, 3) terdapat sebagian pegawai yang belum mengerjakan tugasnya sesuai dengan target dan waktu yang ditetapkan,dan 4) Masih adanya pegawai yang melalaikan pekerjaan.

Berdasarkan beberapa uraian diatas penelitian ini berguna agar adanya info tentang adakah hubungan motivasi berprestasi pegawai dengan kinerja pegawai di Dinas Pendidikan dan Kebudayaan Kabupaten Lima Puluh Kota.

\section{Metode Penelitian}

Jenis penelitian ini adalah penelitian korelasional. tujuan penggunaan penelitian korelasional adalah untuk melihat terdapatnya hubungan motivasi berprestasi dengan kinerja pegawai. Populasinya yaitu keseluruhan pegawai PNS dan non pegawai negeri sipil di dinas tersebut berjumlah 89 orang. Dan sampelnya yaitu 47 orang yang didapat menggunakan slovin formula atau rumus yang diambil dengan cara pemakaian teknik proportional stratified random sampling. Penelitian ini menggunakan angket skala likert dengan 5 pilihan jawaban yang telah dibantu dengan SPSS 16.0. data yang diperoleh dianalisis dengan rumus korelasi produk moment yang dinyatakan dari ( suharsimi, arikunto,2014)

$$
r_{x y}=\frac{N(\Sigma x y)-\left(\Sigma_{x}\right)\left(\Sigma_{y}\right)}{\sqrt{\left\{N \Sigma x^{2}-(\Sigma x)^{2}\right\}\left(N \Sigma y^{2}-(\Sigma y)^{2}\right\}}}
$$

Ket:

Rxy = koefisien korelasi variabel $\mathrm{x}$ dan $\mathrm{y}$

$\mathrm{N}=$ jumlah responden

$\mathrm{X}=$ skor variabel $\mathrm{x}$

$\mathrm{Y} \quad=$ skor variabel $\mathrm{y}$

$\mathrm{XY}=$ jumlah pengalian $\mathrm{x}$ dan $\mathrm{y}$

$\mathrm{X}^{2}=$ jumlah kuadrat $\mathrm{X}$ 
$\mathrm{Y}^{2}=$ jumlah kuadrat $\mathrm{y}$

\section{Hasil dan Pembahasan}

Data penelitian keterkaitan hubungan kedua variabel yaitu bisa dilihat berikut ini:

1. Data motivasi berprestasi

Skor motivasi berprestasi yang diperoleh menyebar dari poin terendah 97 hingga 166, namun perlu diperhatikan bahwa kategori minimal 30 dan poin ideal 150. Dari penelitian dan pengolahan data yang dilakukan di dapat skor rata 131,92, median 194, modus 318,16 serta standar deviasi 17,86.

Tabel 1. Distibusi Frekuensi Data Variabel Motivasi Berprestasi

\begin{tabular}{|c|c|c|c|}
\hline Class Interval & $\mathbf{F}$ & $\begin{array}{c}\% \text { Frekuensi } \\
\text { Absolut }\end{array}$ & $\begin{array}{c}\text { Frekuensi } \\
\text { Relative }\end{array}$ \\
\hline $157-166$ & 3 & $6,38 \%$ & \multirow{3}{*}{$44,67 \%$} \\
\hline $147-156$ & 8 & $17,02 \%$ & \\
\hline $137-146$ & 10 & $21,27 \%$ & \\
\hline 127-136 & 7 & $14,89 \%$ & $14,89 \%$ \\
\hline $117-126$ & 6 & $12,76 \%$ & \multirow{3}{*}{$40,41 \%$} \\
\hline $107-116$ & 8 & $17,02 \%$ & \\
\hline $97-106$ & 5 & $10,63 \%$ & \\
\hline Jumlah & 47 & $100 \%$ & $100 \%$ \\
\hline
\end{tabular}

Berdasarkan Tabel 1 di atas, maka 44,67\% responden menyatakan bahwa motivasi berprestasi di dinas tersebut diatas perolehan poin rata-rata, serta terdapat $14,89 \%$ responden menyatakan motivasi berprestasi berada di bawah poin rata-rata, dan 40,41\% motivasi berprestasi berada pada skor rata-rata.

Berdasarkan hasil dari mengolah data dari angket variabel motivasi berprestasi (X) dengan cara melakukan pembandingan poin mean sama poin tertinggi dikalikan 100, jadi nilai dari mean131,92 dibagikan dengan skor maksimal 150, maka akan memperoleh angka $0,879 \times 100=87,9$. Keterangan tersebut menjelaskan motivasi berprestasi di dinas tersebut mendapat categori "Tinggi" yaitu sebesar $=$ $87,9 \%$.

Untuk melihat rata-rata per indikator dari motivasi berprestasi bisa dicek pada tabel 2.

Tabel 2. Tingkat Capaian Per Indicator Motivasi Berprestasi

\begin{tabular}{|l|l|c|c|c|}
\hline No & \multicolumn{1}{|c|}{ Indicator } & Rata-Rata & $\begin{array}{c}\text { Peringkat } \\
\text { Capaian }\end{array}$ & Categori \\
\hline 1. & Tanggung Jawab & 3,83 & $76 \%$ & Cukup Tinggi \\
\hline 2. & Mempertimbangkan resiko & 4,08 & $81 \%$ & Tinggi \\
\hline 3. & Kreatif- inovatif & 3,93 & $78 \%$ & Cukup Tinggi \\
\hline 4 & Umpan balik & 3,41 & $68 \%$ & Cukup Tinggi \\
\hline 5 & Waktu penyelesaian tugas & 3,80 & $76 \%$ & Cukup Tinggi \\
\hline 6 & Tujuan yang realistis & 3,93 & $78 \%$ & Cukup Tinggi \\
\hline & Rata-rata total & $\mathbf{3 , 8 3}$ & $\mathbf{7 6 \%}$ & Cukup Tinggi \\
\hline
\end{tabular}

Berdasarkan Tabel 2 dapat dilihat bahwa skor tertinggi terdapat pada indikator mempertimbangkan resiko yaitu $81 \%$. Sedangkan skor terendah terdapat pada indikator umpan balik yaitu $68 \%$. Secara umum skor rata-rata motivasi berprestasi di Dinas Pendidikan dan Kebudayaan Kabupaten Lima Puluh Kota adalah $76 \%$. Artinya secara umum motivasi berprestasi di dinas tersebu sudah dikatakan cukup tinggi. Maka dari itu, untuk skor terendah yaitu umpan balik di dinas itu perlu diperhatikan serta ditingkatkan lagi, begitu juga dengan indikator yang lain semuanya harus ditingkatkan lagi.

2. Data kinerja pegawai

Skor/poin kinerja pegawai yang diperoleh tersebar dari poin terendah 91 hingga 167, sedangkan kategori terendah 30 dan poin ideal 150. Dari mengelola data secara umum didapat skor mean 134,38, median 137,25, modus 142,99 serta standar deviasi 19,91.

Tabel 3. Distribusi Frekuensi Data Variabel Kinerja Pegawai

\begin{tabular}{|c|c|c|c|}
\hline Kelas interval & F & \% Frekuensi Absolut & Frekuensi Relatif \\
\hline $157-167$ & 9 & $19,14 \%$ & \multirow{2}{*}{$53,17 \%$} \\
\hline $146-156$ & 6 & $12,76 \%$ & \\
\hline $135-145$ & 10 & $21,27 \%$ & $12,76 \%$ \\
\hline $\mathbf{1 2 4 - 1 3 4}$ & $\mathbf{6}$ & $12,76 \%$ & \\
\hline
\end{tabular}




\begin{tabular}{|c|c|c|c|}
\hline $113-123$ & 8 & $17,02 \%$ & \multirow{3}{*}{$34,03 \%$} \\
\hline $102-112$ & 6 & $12,76 \%$ & \\
\hline $91-101$ & 2 & $4,25 \%$ & $\mathbf{1 0 0 \%}$ \\
\hline Jumlah & $\mathbf{4 7}$ & $\mathbf{1 0 0 \%}$ & \\
\hline
\end{tabular}

Berdasarkan Tabel 3 di atas, maka 53,17\% responden menyatakan bahwa kinerja pegawai di dinas diatas skor rata-rata, sementara $12,76 \%$ responden mengatakan kinerja pegawai ada di bawah rata-rata, dan 34,03\% kinerja pegawai pada skor rata-rata.

Didasari hasil mengolah data dari variabel Y dilakukan dengan pembandingan poin rata dengan poin tertinggi dikalikan 100, di dapat 134,38 dibagikan poin tertinggi 150, di dapat hasil 0,895 $\times 100=89,58$. Artinya kinerja pegawai di dinas ada pada categori "Tinggi" yaitu sebesar $=89,58 \%$.

Untuk itu dapat melihat hasil rata-rata setiap indikator dari kinerja pegawai dapat dilihat pada Tabel 4.

Tabel 4. Tingkat Capaian Per Indicator Kinerja Pegawai

\begin{tabular}{|l|l|c|c|c|}
\hline No & \multicolumn{1}{|c|}{ Indikator } & Rata-Rata & $\begin{array}{c}\text { Peringkat } \\
\text { Capaian }\end{array}$ & Categori \\
\hline 1. & Kuantitas & 3,73 & $74 \%$ & cukup tinggi \\
\hline 2. & Kualitas & 3,68 & $73 \%$ & cukup tinggi \\
\hline 3. & Kerja sama & 3,16 & $63 \%$ & Kurang tinggi \\
\hline & \multicolumn{1}{|c|}{ Rata-rata total } & $\mathbf{3 , 5 2}$ & $\mathbf{7 0 \%}$ & Cukup tinggi \\
\hline
\end{tabular}

Berdasarkan Tabel 4 dapat dilihat bahwa skor tertinggi terdapat pada indikator kuantitas yaitu $74 \%$. Sedangkan skor terendah terdapat pada indikator kerjasama yaitu 63\%. Secara umum skor rata-rata kinerja pegawai di Dinas Pendidikan dan Kebudayaan Kabupaten Lima Puluh Kota adalah 70\%. Artinya secara umum kinerja pegawai di dinas sudah dikatakan cukup tinggi. Maka dari itu, untuk skor terendah yaitu kerja sama perlu diperhatikan serta ditingkatkan lagi, begitu juga dengan indikator yang lain semuanya harus ditingkatkan lagi.

3. Uji Normalitas Data

Maka diperoleh hasil perhitungan kedua variabel motivasi berprestasi dengan kinerja pegawai bisa di cek pada Tabel 5.

Tabel 5. Rangkuman hasil dari uji normalitas data

\begin{tabular}{|c|c|c|c|c|}
\hline \multirow{2}{*}{ Variabel } & \multirow{2}{*}{$\chi^{2}$ Hitung } & $\chi^{2}$ Tabel & \multirow{2}{*}{ Db } & \multirow{2}{*}{ Penafsiran } \\
\cline { 3 - 3 } & & $\alpha=0,05$ & & \\
\hline Motivasi Berprestasi & 6,356 & 9,488 & 4 & Normal \\
\hline Kinerja Pegawai & 9,5 & 9,488 & 4 & Normal \\
\hline
\end{tabular}

Pada Tabel 5 menggambarkan bahwasanya $\chi^{2}$ hitung yang telah didapat pada uji normalitas di atas lebih kecil dari $\chi^{2}$ tabel pada taraf signifikan yang dipakai $\alpha=0,05$. Ini menjelaskan bahwa kedua variabel (X) dan variabel (Y) berdistribusi normal.

4. Pengujian hipotesis

Hasil yang diperoleh $r_{\text {hitung }}=0,754>r_{\text {tabel }}=0,288$ pada taraf kepercayaan $95 \%$, dengan demikian dapat diartikan terdapat hubungan motivasi berprestasi dengan kinerja pegawai.

Untuk melihat keberartian hubungan variabel X dan Y maka dilakukan uji coba t. Berdasarkan hasil perhitungan diperoleh $t_{\text {hitung }}=7,717>t_{\text {tabel }}=2,000$ dengan taraf kepercayaan $95 \%$. Dengan demikian maka kita memperoleh data ada hubungan yang berarti antar motivasi berprestasi sama kinerja pegawai. Perolehan data dapat dilihat dibawah ini:

Tabel 6. Pengujian Korelasi dan Kebertian Variabel X dan Y dengan Uji r dan Uji t

\begin{tabular}{|c|c|c|c|c|c|}
\hline $\mathrm{R}_{\text {hitung }}$ & \multirow{3}{*}{$>$} & $\mathrm{r}_{\text {tabel }}$ & \multirow{2}{*}{$\mathrm{T}_{\text {hitung }} \mathrm{Uji} \mathrm{t}$} & \multirow{3}{*}{$>$} & $\mathrm{T}_{\text {tabel }}$ \\
\hline Moment & & $\alpha=0,05$ & & & $\alpha=0,05$ \\
\hline 0,754 & & 0,288 & 7,717 & & 2,000 \\
\hline
\end{tabular}

Berdasarkan hasil pengujian pada tabel 11, hipotesis riset berbunyi "berartinya hubungan antar motivasi berprestasi dengan kinerja pegawai di dinas Kabupaten Lima Puluh Kota”. Dengan demikian, 
disimpulkan bahwa adanya hubungan yang berarti antar motivasi berprestasi dengan kinerja pegawai di Dinas Pendidikan dan Kebudayaan Kabupaten Lima Puluh Kota.

\section{Pembahasan}

Dari riset terkait Hubungan motivasi berprestasi dengan kinerja pegawai di Dinas Pendidikan dan Kebudayaan Kabupaten Lima Puluh Kota yaitu:

1. Motivasi berprestasi

Hasil penelitian diperoleh indikator umpan balik yang memiliki tingkat capaian terendah. Untuk itu, indikator umpan balik perlu diperhatikan kembali demi kelangsungan kerja pegawai dan memenuhi kebutuhan pegawai dalam bekerja, sehingga mendapatkan hasil pekerjaan yang memuaskan. Untuk memperbaiki motivasi berprestasi pegawai pada indikator umpan balik, maka perlunya upaya-upaya yang harus dilakukan pimpinan serta pegawainya. Upaya yang dilakukan dengan cara menimbulkan kesadaran dalam diri bahwa kita harus bersungguh-sungguh dalam bekerja demi tercapainya tujuan dalam organisasi. (Gistituati, 2009) seorang pegawai yang aktif, kreatif, ulet serta rajin adalah orang atau pegawai yang sudah memiliki motivasi dan dorongan kerja yang tinggi dalam dirinya dan mampu mengatasi kesulitan yang dihadapi dalam pekerjaannya. Motivasi berprestasi sebagai suatu dorongan dalam diri seseorang untuk melakukan atau mengerjakan suatu kegiatan atau tugas dengan sebaik-baiknya agar mencapai prestasi dengan predikat terpuji.

2. Kinerja pegawai

Hasil penelitian diperoleh indikator kerja sama berada pada capaian terendah. Menurut (Sedarmayanti, 2004) mengatakan pengertian ketika seorang pegawai mampu menyelesaikan tugas dalam organisasi serta mampu mempertanggungjawabkan tugas yang dimilikinya maka seorang pegawai sudah memiliki kinerja yang bagus dalam pekerjaan. Untuk memperbaiki kinerja pegawai pada indikator kerja sama, maka perlunya upaya-upaya yang harus dilakukan pimpinan serta pegawainya. Upaya yang dilakukan dengan cara membentuk tim-tim dalam menyelesaikan suatu tugas, sehingga pegawai terbiasa mengerjakan tugas pekerjaan secara bersama dan bersungguhsungguh dalam bekerja demi tercapainya tujuan dalam organisasi.

3. Hubungan motivasi berprestasi dengan kinerja pegawai

Motivasi berprestasi di Dinas Pendidikan dan Kebudayaan Kabupaten Lima Puluh Kota memang merupakan salah satu faktor yang mempengaruhi kinerja pegawai di di Dinas Pendidikan dan Kebudayaan Kabupaten Lima Puluh Kota, meskipun hubungannya masih lemah karena diduga masih terdapat faktor lain yang mempengaruhi kinerja pegawai tersebut. Peran kinerja pada dasarnya adalah kemampuan dan motivasi yang saling berhubungan dorongan terbagi atas sikap dan lingkungan kerja. Maka ada keterkaitan antar motivasi dengan keahlian untuk bekerja. Dari faktor kinerja yang telah dijelaskan diatas, terdapat motivasi (motivation) didalamnya, yang dimana terdapat banyak motivasi dalam sistem kehidupan manusia yang mampu menciptakan lingkup kehidupan sosial yang saling mempengaruhi dan memotivasi.

Jadi dapat disimpulkan, bahwa Motivasi berprestasi dengan kinerja pegawai di Dinas Pendidikan dan Kebudayaan Kabupaten Lima Puluh Kota saling berhubungan, meskipun hubungannya masih lemah karena diduga masih terdapat faktor lain yang mempengaruhi kinerja pegawai tersebut. Faktor lain yang mempengaruhi kinerja pegawai tersebut seperti kualitas, kuantitas dan kerja sama. Begitu juga dengan motivasi berprestasi yang dipengaruhi oleh tanggung jawab dalam bekerja, mempertimbangkan resiko, kreatif dan inovatif, umpan balik, waktu penyelesaian tugas serta tujuan yang realistis.

\section{Kesimpulan}

Hasil riset dan pengujian hipotesis tentang hubungan motivasi berprestasi dengan kinerja pegawai di Dinas Pendidikan dan Kebudayaan Kabupaten Lima Puluh Kota dapat diambil kesimpulan sebagai berikut:

1. Motivasi berprestasi di Dinas Pendidikan dan Kebudayaan Kabupaten Lima Puluh Kota berada pada kategori tinggi yaitu $87,9 \%$. Artinya motivasi berprestasi perlu ditingkatkan lagi agar pegawai di Dinas Pendidikan dan Kebudayaan Kabupaten Lima Puluh Kota dapat melaksanakan tugasnya dengan baik dan benar. 
2. Kinerja pegawai di Dinas Pendidikan dan Kebudayaan Kabupaten Lima Puluh Kota berada pada kategori Tinggi yaitu $89,58 \%$. Artinya kinerja pegawai sudah sesuai dengan harapan, Namun perlu adanya peningkatan agar lebih baik lagi.

3. Terdapat hubungan yang signifikan antar motivasi berprestasi dengan kinerja pegawai dengan perhitungan $r$ hitung $=0,754>r$ tabel 0,288 pada taraf kepercayaan 95\%. Pada keberartian korelasi terdapat hubungan yang signifikan antara motivasi berprestasi dengan kinerja pegawai yaitu $t$ hitung 7,717>t tabel 2,000 pada taraf kepercayaan 95\%. Dengan demikian hipotesis yang diuji dapat diterima.

Berdasarkan kesimpulan diatas dapat dikemukakan saran-saran sebagai berikut :

1. Bagi pimpinan di Dinas Pendidikan dan Kebudayaan Kabupaten Lima Puluh Kota hendaknya lebih memberi perhatian pada peningkatan kinerja pegawai guna untuk meningkatkan motivasi kerja pegawai sehingga tujuan dari organisasi tercapai dengan baik. Jika baik kinerja pegawai maka semakin baik juga motivasi kerja pegawainya.

2. Bagi pegawai untuk dapat menaikan motivasi berprestasi melalui ketekunan dalam bekerja, meningkatkan tanggung jawab dalam bekerja, dan menyesuaikan tujuan individu dengan tujuan organisasi.

Bagi pembaca dan penulis semoga penelitian ini bermanfaat kedepannya.

\section{Daftar Rujukan}

Gistituati, N. (2009). Manajemen Pendidikan Landasan Teori dan Perkembangannya. UNP Press.

Mangkunegara, A. . A. P. (2004). Manajemen Sumber Daya Manusia. Remaja Rosda Karya.

Nelitawati. (n.d.). Motivation and Innovation Role of School's Principal in Improving Teacher Professionalism. International Journal of Counseling and Education, 3(2)(pp. 48-56).

Sedarmayanti. (2004). Sumber Daya Manusia dan Produktivitas Kerja. Mandar Maju. 